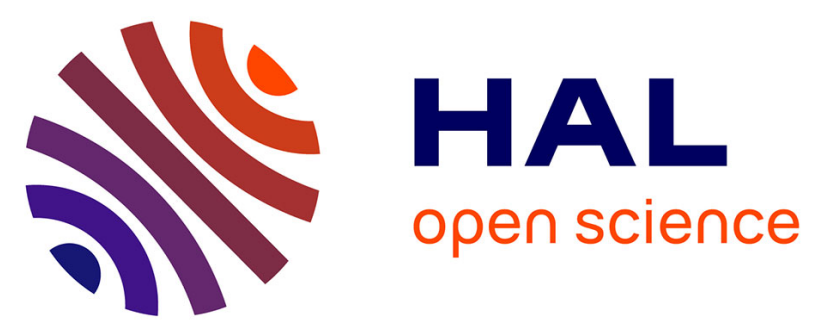

\title{
Multi-modal Thin-Film-Transistor Biosensing Platforms for Bio-medical Investigations: Contribution to Internet-of-Medical-Things
}

Agnès Tixier-Mita, Tieying Xu, Anne-Claire Eiler, Satoshi Ihida, Hiroshi Toshiyoshi

\section{To cite this version:}

Agnès Tixier-Mita, Tieying Xu, Anne-Claire Eiler, Satoshi Ihida, Hiroshi Toshiyoshi. Multi-modal Thin-Film-Transistor Biosensing Platforms for Bio-medical Investigations: Contribution to Internetof-Medical-Things. 10th IEEE CPMT Symposium Japan (ICSJ2021), Nov 2021, Kyoto, Japan. hal03433896

\section{HAL Id: hal-03433896 https://hal.science/hal-03433896}

Submitted on 1 Dec 2021

HAL is a multi-disciplinary open access archive for the deposit and dissemination of scientific research documents, whether they are published or not. The documents may come from teaching and research institutions in France or abroad, or from public or private research centers.
L'archive ouverte pluridisciplinaire HAL, est destinée au dépôt et à la diffusion de documents scientifiques de niveau recherche, publiés ou non, émanant des établissements d'enseignement et de recherche français ou étrangers, des laboratoires publics ou privés. 


\section{Multi-modal Thin-Film-Transistor Biosensing Platforms for Bio-medical Investigations}

\author{
Agnès Tixier-Mita \\ Institute of Industrial Sciences \\ The University of Tokyo \\ Tokyo, Japan \\ agnes@iis.u-tokyo.ac.jp \\ Satoshi Ihida \\ Institute of Industrial Sciences \\ The University of Tokyo \\ Tokyo, Japan \\ ihida@iis.u-tokyo.ac.jp
}

\author{
Tieying Xu \\ LIMMS/CNRS (IRL 2820)-Institute of \\ Industrial Sciences \\ The University of Tokyo \\ Tokyo, Japan \\ tieying@iiis.u-tokyo.ac.jp
}

\author{
Anne-Claire Eiler \\ Institute of Industrial Sciences \\ The University of Tokyo \\ Tokyo, Japan \\ anne@iis.u-tokyo.ac.jp
}

\author{
Hiroshi Toshiyoshi \\ Institute of Industrial Sciences \\ The University of Tokyo \\ Tokyo, Japan \\ agnes@iis.u-tokyo.ac.jp
}

\begin{abstract}
The great evolution of device technology, wireless systems, and artificial intelligence is bringing tremendous and deep change in the field of biomedical. This transformation is participating to the Internet of Medical Things revolution. But, biomedical analyses devices are still limited to not portable devices, single analyses technique or poor spatial sensing. In our research, we used Thin-Film-Transistor technology to realize devices with multi-modal sensing possibility, and with high spatial sensing. We report the results obtained with these devices applied to various sensing and manipulation techniques on biological cells, like dielectrophoresis, electrophysiology, bioimpedance, or electrochemistry. It is expected that they participate to development of digital health.
\end{abstract}

Keywords-Thin-Film-Transistor Technology, Biosensor, IoMT, Digital health, Multi-modal sensing, Active matrix, Multicells culture, Multi-organoid culture.

\section{INTRODUCTION}

The XXIst century is seeing a revolution in the biomedical field in term of diagnostic and investigation tools which will hasten the development of personalized medicine, wearable health devices, homecare and connected health devices [1]. This revolution is first the consequence of the evolution of device technology characterized by miniaturization and integration with electronics for portable and autonomous functioning. Secondly, integration with miniature communication devices is carrying out wireless systems. Thirdly, the progression of artificial intelligence is generating smart systems. In other words, biomedical tools are

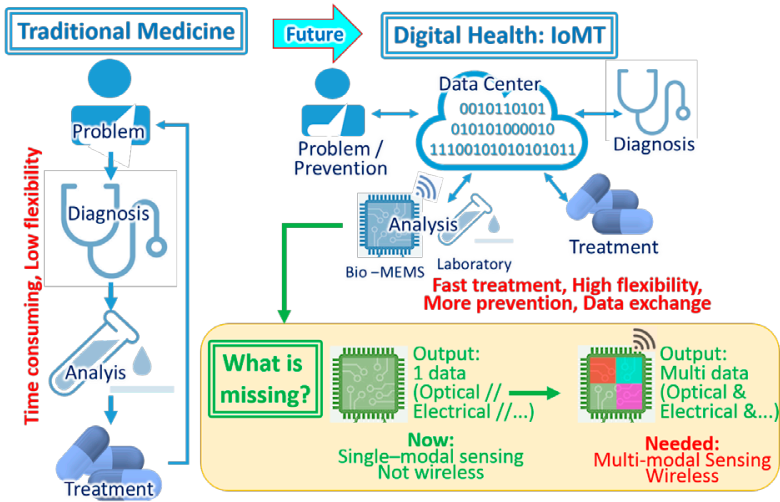

Fig. 1: Evolution of medical procedure: from traditional "water fall" model medicine to IoMT "agile" model medicine. With IoMT, all the elements communicate between them via data center, which stocks commands and data. Wireless multi-modal sensing devices are needed for more efficiency.

This work was supported by the JSPS Core-to-Core Program (A. Advanced Research Network). This work was also supported by the JSPS Challenging Research (Pioneering) no. 21K18869. modernizing based on the maturation of all these elements letting them rush towards the Internet of Medical Things (IoMT) area [2], which is IoT applied to biomedical. The consequence will be faster treatment of the medical information, data exchange easiness, more prevention, and higher flexibility in the investigations (Fig. 1).

The advancement of efficient IoMT devices goes with the evolution of the devices towards multi-modal possibilities, for complex investigations. In that aspect, the platforms developed by Berkley Lights, Inc. are among the most advanced automatic in-vitro analysis and drug discovery tool [3]. However, analyses is performed optically, which prevent the possibility to have accurate sensing and portable tools. As for electrical devices, a great number is already available. But most of them are usually very specific to single application, like glucometers, wearable heart rate sensors or specific disease diagnosis with PCR. It means that systems which combine multi-modal sensing, despite their very attracting possibilities to perform complex analyses, are still in the research phase. Actually, it is still challenging to integrate several sensing elements on the same device due to device spatial limitation, resolution, or incompatibility in the fabrication or analyses techniques. This is particularly true for devices for in-vitro analyses on cell culture.

Our group is using Thin-Film-Transistor (TFT) technology, originally used for Liquid-Crystal-Display (LCD) fabrication, to develop multi-modal devices for in-vitro application,. Substrates with a large area (several centimeter square) covered with high resolution and high density transparent sensors can be obtained with that technology. These thousands of sensors can be specifically dedicated to various sensing applications. We have already demonstrated the possibility to perform: electrophysiology, bio-impedance sensing, electrochemical sensing, and dielectrophysiology on neurons, cardiomyocytes and pancreas cells. These results were obtained with the same TFT-device platform with dedicated instrumentation for each technique.

\section{The Thin-Film-Transistor Device Platform}

TFT technology has more than 50 years history and has been mainly used until now in the fabrication of LCD. With that technology, a large active matrix of thousands to millions of transparent pixels, can be fabricated on any kind of substrate, even plastic or glass. The structure of the devices let it very suitable for biological applications: the pixels can be used as sensors or for electrical interaction and the transparent 


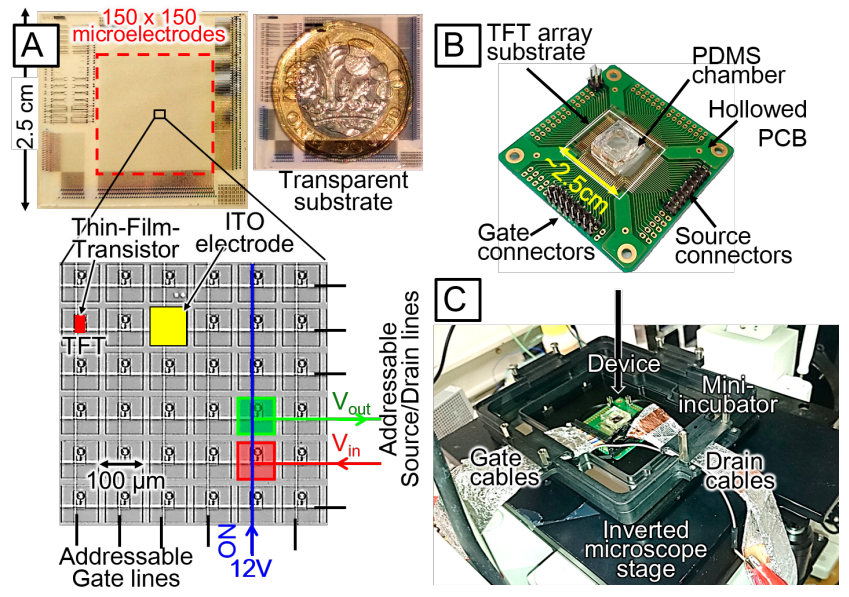

Fig. 2: Working principle. A. Structure of a TFT substrate. Example of a 150x150 matrix array. B. Mounted substrate on a PCB. C. Experimental environment: simultaneous electrical and optical analyses.

glass substrate and pixels are compatible with biology optical observation [4]. An exceptional advantage of these devices is that the whole surface is covered with high density of sensors. As a consequence, any in-vitro cell culture (mono-, multi-cell, or co-culture) can be thoroughly analyzed with almost no spatial limitation. Another consequence is that the different sensors can be dedicated to various sensing techniques for multi-modal analyzes with the same device.

The substrates used for this research consist in a $150 \times 150$ matrix of $100 \mu \mathrm{m}$ square Indium-Tin-Oxide (ITO) microelectrodes controlled by switch TFTs, on a glass substrate. Each substrate is mounted on a PCB board by wirebonding for the connection. A limited number of microelectrodes are connected to adapt the PCB: here $28 \times 28$.

The TFTs consist of three terminals: a gate, a drain, and a source. Gate terminals are column-parallel connected and drain terminals are row-parallel connected. The source terminal of each TFT is connected to one ITO microelectrode. By applying an electric potential to a gate line (column), all TFTs connected to that column are switched ON. With a measurement system or signal generator connected to a drain line (row), the microelectrode at the gate-drain lines intersection can be used for sensing or for applying an electrical signal, respectively. The working principle of the TFT-device platform is shown on Fig. 2.

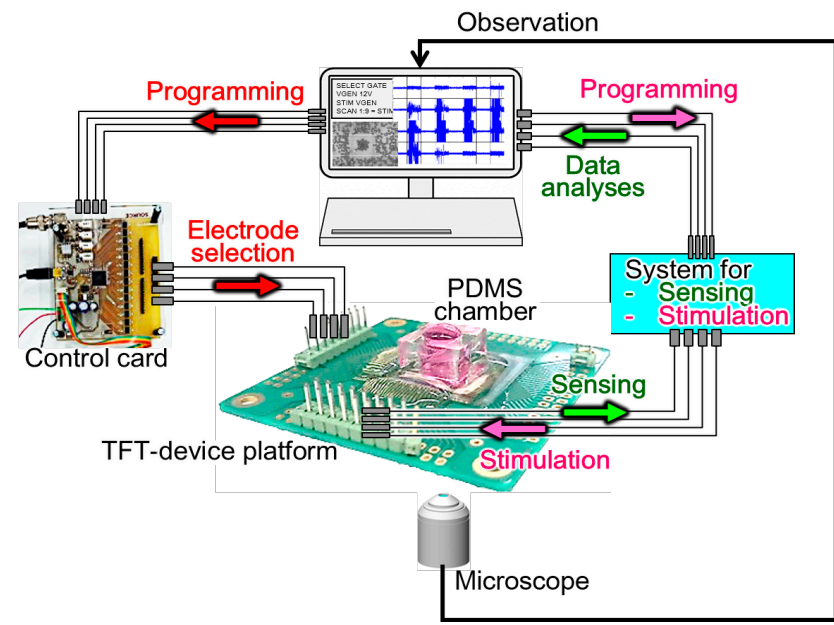

Fig. 3: Scheme of the general set-up for the functioning of the TFT-device platform.

\section{IN-VITRO APPLICATION OF THE TFT-DEVICE PlATFORM}

\section{A. Experimental set-up}

The general set-up used for experiments is described on Fig.3. An inverted microscope is used for simultaneous optical observation during experiments. A programmable control card is used to select the gate line, and eventually scan them. According to the experiment, an electrical instrument is chosen to apply a signal to or to sense from the drain lines. Programming of the instruments and optical and electrical data analysis are performed by a computer.

The TFT-Device Platform has been applied to various invitro applications. Some of the applications were for manipulation of cells on the surface of the platform by dielectrophoresis, others for sensing and analyses of cells by electrophysiology, bioimpedance and electrochemistry. For each application, the same type of substrate was used, but the cells type and the technique required particular preparation of the surface, or particular instrumentation.

\section{B. Cells Manipulation by dielectrophoresis}

Dielectrophoresis is a technique used to manipulate cells on a chip for transportation, separation and also patterning. Actually, cells are dielectric elements on which a force is exerted when they are submitted to a non-uniform electric field. This one can be created by applying an AC voltage to a microelectrode placed in a solution. Cells in the solution feel a dielectrophoretic force which strength and sense depends first of all on the dielectric properties of the cells and the solution. The advantage of the TFT-device is that, thanks to the matrix aspect of the microelectrodes, dielectrophoresis technique can be applied anywhere requested, just by programming. Fig. 4 presents example of results of dielectrophoresis on $\mathrm{C} 2 \mathrm{C} 12$ muscle cells, in a low conductivity $300 \mathrm{mM}$ D-Mannitol solution, when an AC voltage of $20 \mathrm{~V}, 1 \mathrm{kHz}$ was applied to several microelectrodes [5].

\section{Cells Sensing by Bioimpedance and Electrophysiology}

\section{1) Cells monitoring by bioimpedance}

Bioimpedance is a technique to characterize cells by applying an AC signal and measuring the impedance against that signal. The impedance is changing according to the morphology, the type and the healthiness of the cells and the cell culture. It can give information on, for instance, the state of viability, attachment, motion, contamination and so on of cells in a culture. Here to, bioimpedance experiments can be performed anywhere requested by programming. Fig. 5.A. presents typical impedance and phase results of the monitoring of HepG2 liver cells dying on the surface of a TFT-device [6].

\section{2) Cells activity analyses by electrophysiology}

The electrical properties of cells can be characterized by electrophysiology. In particular, cells presenting electrical
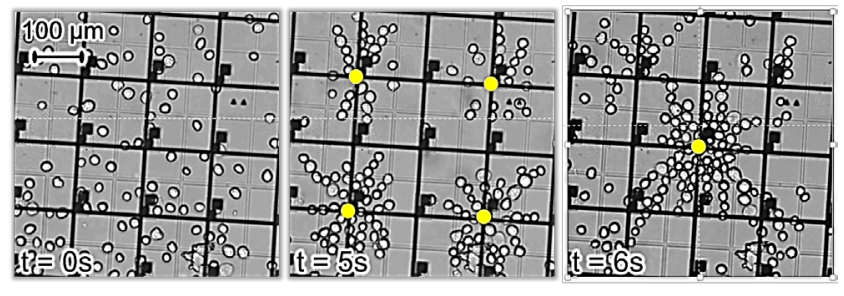

Fig. 4: Dielectrophoresis on C2C12 muscle cells in $300 \mathrm{mM}$ D-Mannitol solution. Applied AC voltage: $20 \mathrm{~V}, 1 \mathrm{kHz}$. [5] 

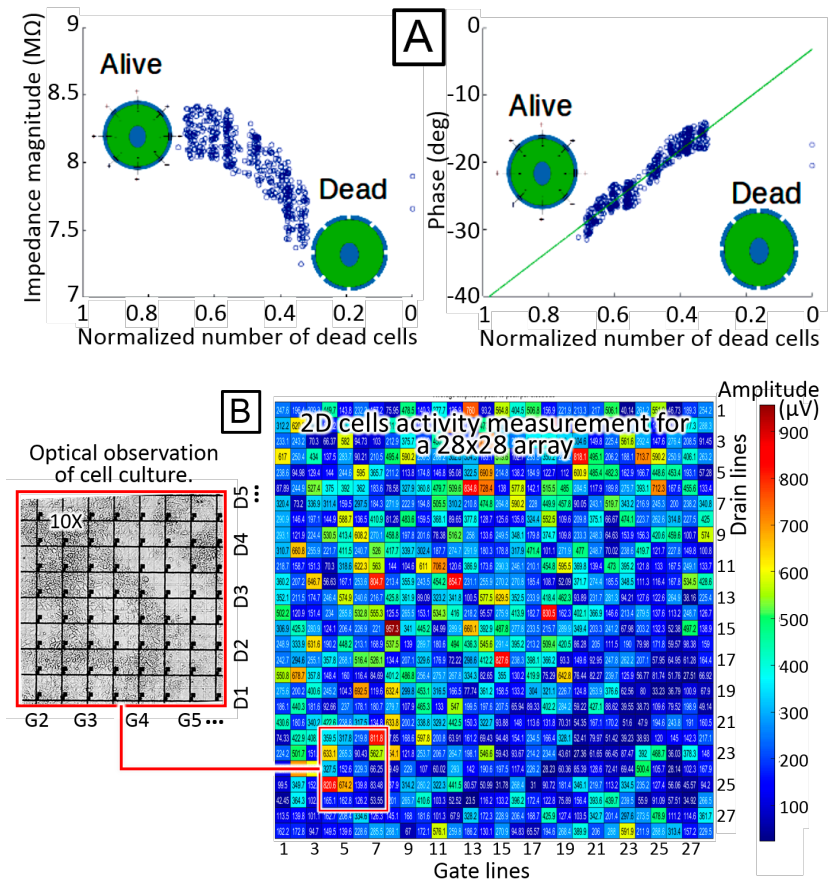

Fig. 5: A. Monitoring of HepG2 liver cells dying on the surface of the TFT-device by bioimpedance sensing. The input AC signal was: $100 \mathrm{mV}, 1 \mathrm{kHz}[6]$. B. Electrophysiology of cardiomyocyte cell culture by selecting a $28 \times 28$ matrix electrode [7].

activity, like neurons, cardiomyocytes or pancreas $\beta$-cells can be analyzed by measuring with microelectrodes the variation of potential enhanced by ion exchange through their membrane. The matrix structure of TFT-devices is very similar to the one of CMOS-MEAs (CMOS-Multi-ElectrodeArrays) devices which are now the most advanced ones for electrophysiology. But, while the sensing surface of CMOSMEAs is limited to 1 or $2 \mathrm{~mm}$ square, the TFT matrix expands on a surface 10 times larger. As a consequence, large cell culture can be investigated. Fig. 5.B. shows results of electrophysiology on a cardiomyocyte cell culture [7].

\section{3) Chemical Sensing}

The authors are also working on the development of chemical sensors with the same type of devices. An impedance human serum albumin sensor has been realized by functionalizing the surface with anti-human serum albumin IgG, based on the same technique as for cell culture monitoring [8]. The smallest concentration detected was $0.3 \mathrm{pM}$.

Finally, the authors demonstrated cyclic voltammetry and amperometry experimental results with the TFT-device, in agreement with results obtained with a standard gold working electrode. Amperometry was performed on Tyramine and the smallest concentration detected was $10 \mu \mathrm{M}$ [7].

\section{CONCLUSIONS AND PERSPECTIVES}

This article has detailed the state-of-the-art of the activities of the authors based on the derivation of the TFT technology from display application to biomedical applications. Various manipulation or sensing techniques can be applied with TFT- devices. Demonstration of the successful manipulation of cells by dielectrophoresis, cell culture monitoring by bioimpedance sensing, electrophysiology of cells as well as biochemical sensing by impedance or electrochemistry was detailed. The great advantage of the TFT-device compared to devices based on microtechnology or CMOS technology resides in the large surface covered with a high density of microelectrodes. Thanks to the large surface, there is no spatial limitation of the cell culture: large cell culture, like multi-cell culture, cell coculture or multi-organoid culture are considered for a close future development. Microfluidic element can also be easily integrated. Another essential aspect is the high density of microelectrodes covering the whole surface thanks to which multi-modal analyses can be performed. Indeed, these microelectrodes can be used for various sensing techniques, as detailed in this article, provided improvement at the instrumentation and programming level to switch easily from one technique to the other. This improvement is also among the priorities of the laboratory. Finally, a last point concerns the extension of the TFT-platform to realize a wireless device. Actually, by upgrading the TFT-device platform as a wireless system, flexibility and efficiency in managing devices and communicating data in real-time will be obtained. For instance, analyses on a cell culture could be checked at distance, and unforeseeable change could be reported directly to the operator.

\section{REFERENCES}

[1] J. Dunn, R. Runge, and M. Snyder, "Wearable and the medical revolution", Personalized Medicine, vol. 15(5), pp. 429-448 September 2018.

[2] A. Gatouillat, Y. Badr, B. Massot, and E. Sejdic, "Internet of Medical Things: A review of Recent Contributions Dealing with CyberPhysical Systems in Medicine", IEEE IoT J., vol. 5(5), pp. 3810-3822, Oct. 2018.

[3] J. Diep, H. Le, K. Le, E. Zasadzinska, J. Tat, P. Yam, R. Zastrow, N. Gomez, and J. Stevens, "Microfluidic chip-based single-cell cloning to accelerate biologic production timelines", Biotech. Progress, e3192, July 2021.

[4] A. Tixier-Mita, S. Ihida, B.-D. Ségard, G.A. Cathcart, T. Takahashi, H. Fujita, and H. Toshiyoshi, "Review on thin-film transistor technology, its applications, and possible new applications to biological cells", JJAP, vol. 55(4S), 04EA08, 2016.

[5] A. Tixier-Mita, S. Ihida, D. Blanchard, M. Shinohara, A-C. Eiler, G-A. Cathcart, P-M. Faure, T. Kohno, Y. Sakai, T. Lévi, and H. Toshiyoshi, "2D Dielectrophoresis Using an Active Matrix Array made by Thin-Film-Transistor Technology", IEEJ Trans. EEE, vol. 14, Issue 9, pp. 1280-1288, July 2019.

[6] G.A. Cathcart, A. Tixier-Mita, S. Ihida, A.-C. Eiler, H. Toshiyoshi, "Non-Mutative Cell Viability Measurement on an IGZO Transparent Thin Film Transistor Electrode Array", IEEJ Trans. Sens. Micromach., vol. 140(8), p. 193-200, August 2020.

[7] A.-C. Eiler, P.-M. Faure, J. Sugita, S. Ihida, D. Zhu, Y. Sakai, K. Fujiu, K. Komori, H. Toshiyoshi, and A. Tixier-Mita, "Application of a ThinFilm Transistor Array for Cellular-Resolution Electrophysiology and Electrochemistry", IEEE Trans. Elec. Dev., vol. 68(4), pp. 2041-2048, April 2021.

[8] D. Zhu, G.A. Cathcart, S. Ihida, H. Toshiyoshi, A. Tixier-Mita, Y. Sakai, and K. Komori, "Towards the development of a label-free multiple immunosensor based on thin film transistor microelectrode array", J. Micromech. Microeng., vol. 31, 115002, September 2021. 